\title{
Underlying Gaps between Environmental Knowledge and Behavior in the City of Toyota: Phase II
}

\author{
Hiroshi Ito ${ }^{1}$ \\ ${ }^{1}$ Department of Economics, Nagoya University of Commerce and Business, Nisshin, Japan \\ Correspondence: Hiroshi Ito, Faculty of Economics, Nagoya University of Commerce and Business, Nisshin, \\ Aichi, 470-0193, Japan. Tel: 81-561-73-2111. E-mail: hito@nucba.ac.jp
}

Received: January 9, 2017

doi:10.5539/ass.v13n3p117

\author{
Accepted: February 3, $2017 \quad$ Online Published: February 15, 2017 \\ URL: http://dx.doi.org/10.5539/ass.v13n3p117
}

\begin{abstract}
This study analyzes underlying gaps between environmental knowledge and behavior in the city of Toyota. A previous study through a focus group interview suggests that Toyota citizens act or do not act on eco-items comprising the city's eco-policy for ecological, economic as well as other reasons such as safety and convenience. Through a combination of questionnaires and interviews with 29 Toyota citizens, the current research extends the previous study and continues to further explore reasons why citizens take or do not take actions on eco-items while they are aware of them. The findings of the current research confirm those of the previous study and provide more insights about why Toyota citizens take or do not take actions on eco-items despite their recognition.
\end{abstract}

Keywords: Toyota City, eco-policy, environmental knowledge, environmental behavior

\section{Introduction}

Toyota was designated by the Japanese government in 2009 as one of the environmental model cities (Toyota City, 2009). A previous study on Toyota's eco-policy showed that although some respondents recognized eco-items such as Ha:mo and the smart house, they do not use Ha:mo or live in the smart house (Ito \& Kawazoe, 2016).

Subsequently, another research project was conducted to explore possible reasons for this lack of action (Ito, 2017). Through a focus group interview with six members of an environmental NGO based in Toyota, this study suggested that the reasons why citizens do not act on eco-items may not solely be ecological or economic but a mixture of both as well as other reasons (e.g., safety and convenience). Also, whereas citizens may not seem fully engaged in the 'eco-items' defined by Toyota, a more careful examination about their actions suggested that they actually take actions in ways that approximate the eco-items. For instance, few citizens own smart houses, but some renovate their houses to make them more environmentally friendly. Installment of solar panels is a prime example. The study concluded that Toyota perhaps would need to broaden the ways that citizens can reasonably act on the eco-items. Although the previous study was useful as a first step to explore reasons why citizens act or do not act on eco-items, the study involved several limitations: the number of participants was limited to six, as a focus group interview method was employed, and the participants were from a single environmental organization in Toyota.

The current research extends the previous study and further continues to explore reasons why citizens take or do not take actions on eco-items while they are aware of them. The current research employs a combination of questionnaires and interviews conducted with 29 Toyota citizens who participated in an eco-event in Toyota. Given the research methodology used and the small number of and characteristics of respondents interviewed, the current research is still exploratory in nature and does not intend to generalize the environmental knowledge and behavior of all Toyota citizens. Instead, its main purpose is to help construct survey questions for a generalizable study at a larger scale in the future.

This study focuses on three eco-themes that Toyota supports to promote its eco-policy: transportation, the urban center, and public welfare and livelihood because these three are the most familiar eco-themes to citizens (Ito \& Kawazoe, 2016). Transportation variables consist of knowledge of next generation cars (NGCs) and Ha:mo. NGCs include electric vehicles (EVs), hybrid electric vehicles (HEVs), and plug-in hybrid vehicles (PHVs). 
Ha:mo is a car sharing system that uses compact EVs for urban short-distance transportation. The urban center variables consist of knowledge of Ecoful Town and the heat island effect. Ecoful Town is a pavilion showcasing eco-living that demonstrates how Toyota tackles challenges and elaborates on eco-strategies. As in any other urban areas, the heat island effect is an issue in Toyota City, as it causes air pollution and deteriorates soil quality (Toyota City, 2016). Public welfare and livelihood variables consist of the smart house and eco-points/eco-family cards. The smart house is a residential building that emits reduced $\mathrm{CO}_{2}$ gas emission and saves energy through the use of renewable energy sources and monitoring of energy consumption (Kim et al., 2015). Eco-points can be accumulated when the eco-family card is presented at certain places such as Ecoful Town and greenly affiliated stores. These points can be exchanged for certain goods, such as stationery, bus tickets, or gift certificates.

\section{Methodology}

\subsection{Sample}

The participants in this research project are 29 Toyota citizens who gathered together at an eco-event called "Inaka to machi no bunkasai" (a cultural festival for rural and urban areas) that took place on November 21, 2016 at Toyota City Station. These participants may not represent the opinions of the general population in Toyota because they have already gone to an eco-event and likely know more about environmental issues and eco-items comprising the eco-policy than the general population. However, they are suitable for fulfilling the purpose of this study because this study seeks the opinions of those who generally know about eco-items comprising the eco-policy (but may not act on them). As Mills (2008) affirms in his study of environmentally active consumers, "it may potentially be much more appropriate and empirically interesting to examine the attitudes of those most predisposed [to the knowledge of the subjects/areas under study]" (Mills, 2008, p. 3).

\subsection{Method}

This study employs a combination of questionnaires and interviews. The principal purpose of this study is to help construct survey questions for future generalizable research at a larger scale. To do so, it is highly advisable to conduct pilot or exploratory studies to collect data to establish potential questions for a generalizable study at a larger scale in the future (Schensul, Schensul, \& LeCompte, 1999). This study is expected to serve this purpose.

\subsection{Procedures}

At the beginning of the research, the author explained to the participants the context of why this study was being conducted. The participants then filled out the questionnaires that asked whether they knew about certain eco-items comprising the eco-policy and whether they acted or not on these items (Table 1). After filling out the questionnaire, respondents were asked why they were aware of certain items or not, and why they act or do not act on these items.

Table 1. Questionnaire items

\begin{tabular}{ll}
\hline Eco-theme & Survey Questions \\
\hline Transportation & Q1. Do you know about NGCs? \\
& Q2. Do you ride NGCs? \\
& Q3. Do you know about Ha:mo? \\
& Q4. Have you used Ha:mo? \\
Qrban Center & Q5. Do you know about the heat island effect? \\
& Q6 Do you take measures against the heat island effect? \\
& Q8. Have you been to the Ecoful Town? \\
Public Welfare and Livelihood & Q10. Do you know about the smart house? \\
& Q11. Do you know about eco-points? \\
& Q12. Do you use eco-points? \\
\hline
\end{tabular}




\section{Results}

Table 2. Socio-demographic factors

\begin{tabular}{|c|c|c|c|}
\hline & & $n$ & $\%$ \\
\hline \multicolumn{4}{|l|}{ Age } \\
\hline & $20-29$ & 2 & (6.9) \\
\hline & $30-39$ & 11 & (37.9) \\
\hline & $40-49$ & 7 & $(24.1)$ \\
\hline & 50 or above & 9 & $(31.0)$ \\
\hline \multicolumn{4}{|c|}{ Gender } \\
\hline & Female & 19 & $(65.5)$ \\
\hline & Male & 10 & $(34.5)$ \\
\hline \multicolumn{4}{|c|}{ Marital status } \\
\hline & Single & 8 & $(27.6)$ \\
\hline & Married & 21 & $(72.4)$ \\
\hline \multicolumn{4}{|c|}{ Education } \\
\hline & High school diploma or equivalent & 14 & $(48.3)$ \\
\hline & University / postgraduate degrees & 15 & $(51.7)$ \\
\hline \multicolumn{4}{|c|}{ Household income } \\
\hline & Low income (less than 20,000 USD) & 5 & $(17.2)$ \\
\hline & Lower middle income $(20,000-50,000$ USD) & 9 & $(31.0)$ \\
\hline & Upper middle income $(50,000-80,000$ USD) & 7 & $(24.1)$ \\
\hline & High income (more than 80,000 USD) & 4 & $(13.8)$ \\
\hline & Unanswered & 4 & (13.8) \\
\hline
\end{tabular}

Table 3. Questionnaire results

\begin{tabular}{lccc}
\hline \multicolumn{1}{c}{ Questions } & Yes & No & Already \\
\hline Q1. Do you consider buying an NGC? & $12(41.4)$ & $11(37.9)$ & $6(20.7)$ \\
Q2. Do you know about Ha:mo? & $18(62.1)$ & $9(31.0)$ & $2(6.9)$ \\
Q3. Do you know about the heat island effect? & $25(82.8)$ & $3(10.4)$ & $2(6.9)$ \\
Q4. Do you know Ecoful Town? & $7(24.1)$ & $2(6.9)$ & $20(69.0)$ \\
Q5. Do you know about the smart house? & $19(65.5)$ & $10(34.5)$ & $0(0.0)$ \\
Q6. Do you know about eco-points? & $11(37.9)$ & $1(3.4)$ & $17(58.6)$ \\
\hline
\end{tabular}

This study analyzed reasons why:

- Respondents consider purchasing NGCs but have not done so;

- They actually have NGCs;

- They recognize Ecoful Town but have not been there;

- They have actually been to Ecoful Town;

- They recognize the smart house but do not live there;

- They recognize Ha:mo but do not use it;

- They actually use Ha:mo; 
- They recognize the Eco-family card but do not use it;

- They use the Eco-family card;

- They recognize the heat island effect but do not take countermeasures; and

- They take countermeasures against the heat island effect.

None of the respondents lived in a smart house, so it was not possible to analyze individuals living in one.

\subsection{Reasons That Respondents Consider Purchasing NGCs But Have Not Done So}

There were 12 respondents who reported that they were thinking of buying NGCs but had not done so. Most of them regarded NGCs as expensive. For instance, one respondent said: "I have once calculated which would be more economical, an NGC or an oil-fuel car. Given the commuting distance to my workplace, the price of gas, and money that would be saved by the use of an NGC, I concluded that an oil-fuel car would be cheaper overall" (30s, woman, married, university graduate, 50,000-80,000 USD).

Another respondent also reported: "I currently work for an environmental NPO and thus know the benefits of NGCs. However, I find them quite expensive. Using an ordinary car is a lot more economical" (30s, man, married, university graduate, more than 80,000 USD).

As is the case with the previous study, some respondents mentioned security reasons for not driving NGCs or preferring light gas fuel cars, commonly called Kei in Japan. One respondent claimed: "Kei is easier to drive than an NGC or an ordinary car, especially inside the city center" (30s, woman, married, university, 20,000-50,000 USD).

\subsection{Reasons That They Actually Have NGCs}

Some respondents reported that they actually drive NGCs: some for ecological reasons, some for economic reasons, and many for both reasons.

One respondent, for example, said: "I am driving an Aqua (Toyota's NGC)...of course, for the environment as well as energy cost efficiency" (50s, woman, married, high school graduate, 50,000-80,000 USD).

Another said: "I am driving a Prius (Toyota's NGC) for ecological reasons...yeah, energy efficiency is a synonym to environmentally friendly, isn't it?" (40s, man, married, high school graduate, N/A).

\subsection{Reasons That They Recognize Ecoful Town But Have Not Been There}

The vast majority of the respondents knew about Ecoful Town. Seven of those who knew it, however, had not been there.

One respondent reported: "I got to know about Ecoful Town from a newspaper but have not been there because it is far from my place" (50s, woman, married, high school graduate, 20,000-50,00 USD). Another respondent said: "I want to go to Ecoful Town because I have heard that there is a good restaurant [Hogaraka], but I don't know what else is there and what I can do there" (30s, woman, married, university graduate, 20,000-50,000 USD).

\subsection{Reasons That They Go to Ecoful Town}

Those who have been to Ecoful Town mentioned the following reasons to visit: 1) to go to a restaurant called Hogaraka, 2) to participate in an event to try out the Mirai, a new NGC from the Toyota Motor Corporation, and 3 ) to received eco-points. Below I present remarks from some participants with regard to these reasons.

\subsubsection{Restaurant Hogaraka}

"I have been there because there is a good restaurant [Hogaraka] (30s, man, married, university graduate, more than 80,000 USD)."

"I have been there to have lunch with my friend at a restaurant [Hogaraka] (30s, woman, married, university graduate, 50,000-80,000 USD)."

\subsubsection{Events to Try Out the Mirai}

"I have been to Ecoful Town because there was an event that visitors could try out the Mirai" (a new NGC of TMC) (20s, man, single, university graduate, less than 20,000 USD).

"I have been there because there was an event where we could try out the Mirai" (50s, man, married, high school graduate, 20,000-50,000 USD).

\subsubsection{Eco-points / Eco-family Cards}

"What motivates us to go there is that they give us eco-points by just visiting" (30s, woman, single, high school 
graduate, 20,000-50,000 USD).

"We go there often because every time we go, they give us eco points and we can exchange eco-points for goods such as toilet paper" (50s, woman, married, high school graduate, 50,000-80,000 USD).

\subsection{Reasons That They Recognize the Smart House But Do Not Live in One}

Approximately two-thirds of respondents knew about the smart house, but none actually lived in one. Three reasons were provided: 1) their houses had recently been bought or built, 2) smart houses are expensive, and 3) they live in mansions. Below I present some reasons mentioned during the interview.

\subsubsection{Their Houses Being Recently Bought or Built}

"I want to live in a smart house, but our house is still new" (50s, man, married, high school graduate, 20,000-50,000 USD).

"Our house, which is not a smart house, has just been recently built...it has been installed with solar panels, though" (50s, woman, married, high school graduate, 50,000-80,000 USD).

\subsubsection{Smart Houses Being Expensive}

"I want to live in a smart house, but I think that it is expensive" (30s, woman, married, university graduate, 20,000-50,000 USD).

"I want to live in a smart house but it is expensive to buy and maintain it" (40s, woman, married, community college graduate, 50,000-80,000 USD).

\subsubsection{Living in Mansions}

"We live in a mansion. Although this may not be called a smart house. It is energy efficient and ecological, with an adequate thermal insulation system inside" (30s, woman, married, university graduate, 50,000-80,000 USD).

\subsection{Reasons that Ha:mo Is Recognized But Not Used}

As is the case with the smart house, quite a few respondents knew about Ha:mo. However, few actually use it, mainly for three reasons: 1) they have their own cars, 2) the registration process is troublesome, and 3) Ha:mo stations are far from their home. I will present below some comments mentioned in regards to each of these reasons.

\subsubsection{Already Having Cars}

One respondent, for example, said: “I won't use Ha:mo because I have a car" (40s, woman, married, high school graduate, 50,000-80,000 USD).

Another echoed her stating: “I don’t use Ha:mo because I have a Prius. When I just go around the city center, I use my bicycle because it is more economical and ecological than using my car or Ha:mo." (50s, woman, married, university graduate, 20,000-50,000 USD).

\subsubsection{Troublesome Registration Process}

Some respondents found the registration process of Ha:mo troublesome.

One respondent reported: "I have registered myself in the Ha:mo system. Yet, I still have to receive training and find it troublesome. I already have my own car, you know..." (30s, man, single, graduate school graduate, 20,000-50,000 USD).

Another respondent also claimed: "The registration process is troublesome. If the process were easier, I would like to use it" (40s, man, married, high school, N/A).

\subsubsection{Ha:mo Stations Being Far from Home}

Despite the city's effort to set up Ha:mo stations, many complained that they do not see them around their homes. One respondent reported: "If there was a Ha:mo station near my house, I might use it because using Ha:mo might be cheaper than using my own car. However, I currently find it troublesome to go all the way to get a car at the Ha:mo station because they are far from my home and workplace" (30s, woman, married, university graduate, 20,000-50,000 USD).

Another respondent claimed: "If there were a Ha:mo station near my house, I might use it in the future. It would be economical because I would not have to pay for car insurance as well as a car itself" (40s, woman, married, university graduate, less than 20,000 USD). 


\subsection{Reasons That They Use Ha:mo}

There were two respondents who actually use Ha:mo.

One of them said: "I am using it...yeah, when I go for a drink, I use it and leave it at one of the Ha:mo stations" (30s, man, single, postgraduate, more than 80,000 USD).

The other said: "Although I have a car, I intend to use it as much as possible because it is environmentally friendly" (40s, man, married, university graduate, N/A).

\subsection{Reasons That They Recognize the Eco-family Card But do Not Use It}

Some respondents are well aware of the Eco-Family Card, but they themselves do not use one because Toyota set a one-family one-card policy.

"I am not using it, but my husband does. I got to know about eco-points at a recycling center" (40s, woman, N/A, $\mathrm{N} / \mathrm{A})$.

"I don't have it myself, but my family does" (20s, woman, single, high school graduate, less than 20,000 USD).

3.9 Reasons That They Use the Eco-family Card

The only reason reported to use the Eco-Family card was to receive points and acquire goods in return, though receiving points can be considered an environmentally friendly act.

"I am using it...just for points" (40s, woman, married, university graduate, less than 20,000 USD).

\subsection{Reasons That They Use the Heat Island Effect but Do Not Take Measure against It}

The large majority of respondents (approximately 90\%) at least recognized the heat island effect itself, but only two respondents had done something against it. One respondent, for example, claimed: "I know the heat island effect is bad and have to do something, but I don't know what I can do" (50s, man, married, N/A, 20,000-50,000 USD).

"There must be some countermeasures such as preserving rice fields that would prevent temperatures from rising. But this is not what I can do" (50s, woman, married, high school graduate, 50,000-80,000 USD).

\subsection{Reasons That They Take Measures against the Heat Island Effect}

As mentioned above, two respondents reported that they had taken countermeasures against the heat island effect. One, for example, reported: "I am using planters as a measure against the heat island effect because I know the heat island effect exists in Toyota" (30s, woman, married, graduate school graduate, 50,000-80,000 USD).

Another respondent claimed: "I often plant trees. This is a countermeasure against the heat island effect, isn't it?" (20s, men, single, university graduate, less than 20,000 USD).

\section{Discussion}

Findings of the current study confirm those of the previous study and still provide some new insights into reasons that citizens act or do not act on eco-items.

The current research supports the findings of the previous study. For example, citizens do not buy NGCs due to their high costs (i.e., NGCs are expensive) and safety concerns (i.e., Kei are easier to drive); citizens do not go to Ecoful Town because it is located far from their homes and they lack information about Ecoful Town; citizens do not live in smart houses because they have recently built houses or live in apartments/mansions, as well as smart houses are expensive; citizens do not use Ha:mo due to reasons of inconvenience (i.e., no Ha:mo stations are not closer to their homes) or the troublesome registration process; citizens do not have the Eco-Family Card because the card has a "one card per family" policy; citizens do not take any countermeasures against the heat island effect because they do not know what they can do. The current study also provided some new insights into citizens' actions on eco-items: citizens go to Ecoful Town because they can try Mirai (TMC's NGC) and also receive eco-points.

These findings suggest that some modifications could be made on Toyota City's eco-policy. Kei, for example, is not an NGC but may be as energy efficient and thus ecological as an NGC. If NGCs are encouraged to use for ecological reasons, citizens using Kei may already satisfy this requirement. Those who have not been to Ecoful Town have not been informed what is there and whay they can do there. The city government should provide citizens with more information about attractions and activities. No respondents reported that they lived in smart houses because their houses are not considered smart houses. However, some respondents claimed that they have installed solar panels on their houses. This type of house modification should also count as contribution to the eco-policy. Ha:mo has not been prevalent because citiziens already have cars, the Ha:mo stations are far from 
their places, or the registration process is troublesome. While it is infeasible to install the stations in all areas in Toyota, more stations should be allocated, especially within eco-related organizations, such as environmental NPOs or recycle stations. The city government also should abandon the "one Eco-Family Card per family" policy and allows each individual to have an Eco-Family Card, as may respondents claimed that they did not have a card because their family members already have one. There are also some measures that citizens can take against heat island effects. For instance, placing green curtains (planters) on and around their house buildings are not difficult. The city government should provide citizens with more information about simple countermeasure as such.

It is important to note that whereas the eco-policy needs to be flexible enough that it permits citizens to act on eco-items in a way that is possible within the context of their lives, the goal is actual action on making Toyota City a more environmentally friendly city. That goal has to be achieved by realizing that citizens will approach acting on eco-items in different ways.

The current research is exploratory in nature due to its research methodology and the small number of and characteristics of participants. In order to collect data from the more general public and generalize the findings, future research should be conducted at a larger scale with a wider variety of respondents. The reasons to act or not act on eco-items in both the previous and the current studies can be adapted and placed into the survey questions for future studies. Based on these findings, tentative survey questions are constructed for future research (See Appendix). These survey questions are expected to serve for this future study.

\section{Acknowledgments}

I would like to thank Mr. Ryuji Sakamoto from Eco-T for his support to this study. I also thank Mr. Ezra Antone Greene from University of British Columbia for editing this paper.

\section{References}

Ito, H., \& Kawazoe, N. (2016). A Review of Toyota City's Eco-policy: Changes of citizens' awareness between 2012 and 2015. Urban Research and Practice, 11(1), 1-18. DOI: 10.1080/17535069.2016.1254676.

Ito, H. (2017). Underlying gaps between environmental knowledge and behavior in the city of Toyota. Asian Social Science, 13, 82-88.

Kim, S-K., Lee, S-J., Kwon, H. J., \& Ahn, M. (2015). Zero-energy Home Development in Korea: Energy-efficient and Environmentally Friendly Design Features and Future Directions. Housing and Society, 42(3), 222-238. DOI: $10.1080 / 08882746.2015 .1121682$

Mills, M. K. (2008). Environmentally-active consumers preference for zero-emission vehicles: Public sector and marketing implications. Journal of Nonprofit and Public Sector Marketing, 19(1), 1-33. DOI: 10.1300/J054v19n01_01

Schensul, S., Schensul, J., \& LeCompte M. D. (1999). Essential Ethnographic Methods: Observations, Interviews, and Questionnaires. New York: Rowman \& Little Field Publishers, Inc.

Toyota City. (2009). Summary of Action Plans towards an Environmental Model City. Retrieved from http://www.city.toyota.aichi.jp/division/an00/an06/1252190/02gaiyou.pdf.

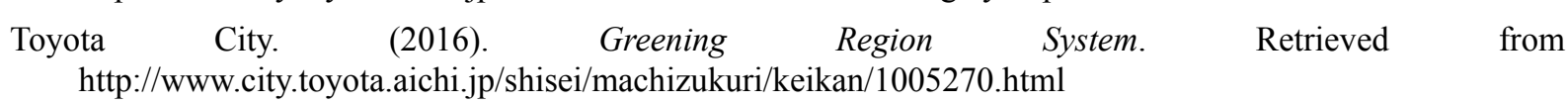

\section{Appendix}

Q1. Are you driving NGCs such as EVs and PHVs?

Yes $\square$ No

For those who checked Yes in Q1, why do you drive an NGC? Please select one or more reasons or add other reasons.

NGCs are cost effective.

NGCs are environmentally friendly.

Other (

For those who checked No in Q1, why don't you drive an NGC? 
NGCs are expensive.

Kei are easier to drive than NGCs.

I am not interested in environmental protection.

Other (

Q2. Do you use Ha:mo?

$\square$ Yes $\square$ No

For those who checked Yes in Q2, why do you use Ha:mo? Please select one or more reason or add other reasons.

Ha:mo is cost effective.

Ha:mo is environmentally friendly.

Ha:mo is convenient.

Other (

For those who checked No in Q2, why don't you use Ha:mo?

$\square \quad$ I already have a car.

Ha:mo stations are far from my home or work place.

The registration process is troublesome.

$\square$ Other (

Q3. Do you live in a smart house?

$\square$ Yes $\square$ No

For those who checked Yes in Q3, why do you live in a smart house? Please select one reason or add other reasons.

Smart houses are energy efficient and cost effective.

Smart houses are environmentally friendly.

$\square$ Other (

For those who checked No in Q3, why don't you drive live in a smart house?

$\square$ Smart houses are expensive.

$\square$ I bought or built my house recently.

$\square$ I live in an apartment or mansion.

Other (

Q4. Do you use the eco-family card?

Yes $\square$ No

For those who checked Yes in Q4, why do you use the eco-family card? Please select one reason or add other reasons.

I can get eco points and receive goods in return.

$\square$ The eco-family card is environmentally friendly.

Other (

For those who checked No in Q4, why don't you use the eco-family card?

$\square$ Another family member has it (because Toyota set a one-family one-card policy).

The registration process is troublesome.

I do not know what I can do with the eco-family card and/or eco-points.

Other (

)

Q5. Do you go to Ecoful Town?

$\square$ Yes $\square$ No

For those who checked Yes in Q5, why do you go to Ecoful Town? Please select one reason or add any reasons.

$\square$ There is a restaurant (Hogaraka) there. 
I can try driving NGCs.

I can receive eco-points.

Other (

For those who checked No in Q5, why don't you go to Ecoful Town?

$\square$ I don't know what is there.

$\square$ It is far from home.

$\square$ Other (

Q6. Do you take any measures against the heat island effect?

$\square$ Yes $\square$ No

For those who checked Yes in Q6, what do you do to reduce the heat island effect? Please select one reason or add other reasons.

$\square$ I place planters.

$\square$ I plant trees.

$\square$ Other (

For those who checked No in Q6, why don't you take measures against the heat island effect?

$\square \quad$ I don't know what I can do.

$\square$ I am not interested in preventing the heat island effect.

Other (

\section{Copyrights}

Copyright for this article is retained by the author(s), with first publication rights granted to the journal.

This is an open-access article distributed under the terms and conditions of the Creative Commons Attribution license (http://creativecommons.org/licenses/by/4.0/). 